\title{
Do psychologists study behaviour?
}

\begin{abstract}
Although social psychology is defined as the science that explores the social behaviour of people, today's research, which is devoted to this matter, is primarily (or almost exclusively) focused on highly specific behaviours that Baumeister, Vohs and Funder wittily called "finger movements". The point is that psychologists most often ask people to fill in various scales and questionnaires and/or to imagine that they found themselves in some situation and answer how they would behave in it. The author of the
\end{abstract}

article asks a question about the reasons for this state of affairs, and also claims that psychology should return to examining real human reactions, and not only verbal declarations about how a person would react in a particular situation.

\section{KEY WORDS}

methodology; social psychology; health psychology; science of psychology 


\section{DO SOCIAL PSYCHOLOGISTS STUDY BEHAVIOUR?}

In recent years, there have been a number of extremely important initiatives aimed at pulling social psychology out of a clear regression. The famous Stapel scandal - a star of social psychology, author of many articles published in the most prestigious scientific journals, who, as it turned out, invented the results of his alleged experiments while sitting at his desk - was a real shock for many social psychologists. However, its advantage was that it led to a serious dispute among psychologists (not only social ones, by the way). The conclusions of this dispute led our environment to paying more attention to the effect size parameter than to the significance of the differences between mean values and the calculation of the number of people who should take part in the research. Importantly, also a genuine wave of replication studies began. An article aimed at evaluating whether a classical effect is replicable has no longer been treated as a "second-class manuscript". Psychologists seem to have finally understood that it is only by replicating a certain regularity multiple times that we can assume that it really exists. There also appeared the idea of pre-registration of planned experiments, which, in my opinion, was controversial. And although it cannot yet be said that the state of social psychology is clearly and unequivocally better than a decade or several decades ago (see Motyl et al., 2017), the very developing debate on the condition of our discipline and the growing awareness of existing problems are phenomena of fundamental importance.

However, the aim of this article is to draw attention to an entirely different issue, which is also related to the crisis of social psychology. Before the scandal of Stapel's frauds broke out, an article by Baumeister, Vohs, and Funder (2007) had been published in Perspectives on Psychological Science under the telling title "Psychology as the science of self-reports and finger movements". The authors of that manuscript pointed out that although psychology is defined as the science of behaviour, behaviour today is not the main focus of its attention. While zoopsychologists and developmental psychologists do indeed observe and analyse behaviour (as the authors jokingly suggest, perhaps because they cannot get their subjects - animals and small, illiterate children - to fill in questionnaires), in the case of social psychology, behaviour other than filling in questionnaires, hitting computer keyboard keys or clicking the mouse is rare. The authors reviewed the latest at that time (January 2006) issue of the fournal of Personality and Social Psychology (FPSP; the flagship journal of this discipline) and stated that finger movements (either on a keyboard, or holding a pencil or a ballpoint pen) are actually almost the only manifestations of behaviour empirically explored by social psychologists.
Several years later I decided to check whether something in this matter has changed (Doliński, 2018a). Nevertheless, unlike Baumeister, Vohs, and Funder, I decided not to focus on a single issue of the journal, but to review what is presented in the entire volume. Each volume of the fournal of Personality and Social Psychology consists of 6 issues. The one analysed by me contained 49 articles. It turned out that the proportion of behavioural studies (other than based on answering the questionnaire using a keyboard or paper and pencil) to all empirical studies presented in these texts was about $6 \%$. One could ask whether the JPSP is not, from this perspective, a specific journal, focusing, for example, on such issues as stereotypes, prejudices, attitudes and values, which would clearly justify the lack of interest of the authors of this journal in real behaviour. However, an analysis of the content of other leading psychological journals in the world (Doliński, 2018b) shows that the aversion of social psychologists to studying real behaviours is a state independent of the journal we take into account. The point is, an alarmingly low percentage of studies on real behaviours also applies to such titles as the European fournal of Social Psychology, fournal of Experimental Social Psychology, Personality and Social Psychology Bulletin, or Social Psychological and Personality Science. To be more precise, it applies to all the titles that I have analysed in this regard.

Of course, there is a question about the reason for such a drastic departure of social psychology from the study of real behaviour. Baumeister et al. (2007) estimate that in 1976 about $80 \%$ of the papers published in $7 P S P$ were devoted to behavioural research. Ten years later this percentage was already more than three times lower! Later on it kept decreasing gradually and consistently, until it reached the level of several percent in 2006. As we can see, today, practically speaking, there is almost no such research at all...

The fact that the departure from behavioural research took place in the 1970 s seems to be related to the so-called cognitive revolution taking place at that time in social psychology. Social psychologists began to apply knowledge about information processing, attention, or memory when explaining the causes of human behaviour. Focusing on what can be measured, rather than observed naturally in a direct way, also resulted in a decrease in psychology's interest in certain issues and an increase in interest in others. And so, psychologists started to examine such problems as altruism and aggression (in other words, behaviour), as well as, more and more often, stereotypes or judgements about the social world (in other words, beliefs).

It also seems that, regardless of this cognitive revolution, in recent decades psychology has become more interested not in determining causal re- 
lationships (i.e., when a certain behaviour appears), but in the psychological mechanisms that trigger these behaviours. In other words, psychology has focused on why a person behaves in a certain way in a specific situation, which in itself should be assessed unequivocally positively. The problem is that in such a situation it was more convenient to place the respondent at a desk, ask them to imagine that they are doing something (or to decide what they are going to do) and to ask them a number of questions, aimed at searching for the mechanisms which trigger behaviours.

Of course, it would not be a problem if people's declarations about how they would behave coincided with their real behaviour. However, there is a lot of evidence that this is not the case in many situations. In a survey commissioned by Deutsche Bank (2014), respondents were asked what they would spend five million on if they won such a sum in a game of chance or inherited it. $27.5 \%$ of the respondents declared that they would give a large part of it to the poor. The reality shows, however, that winners very rarely donate even a part of their winnings to charity (Kaplan, 1987). Significant discrepancies between the declaration of one's own behaviour and the actual behaviour are also revealed by psychological research. For example, Tomasz Grzyb (2016) conducted a study on the mechanism of distribution of responsibility, during which he investigated how the number of people sitting in a railway compartment affected the likelihood that the subject would react when one of the passengers robbed a woman who had left the compartment for a moment. It turned out, in accordance with the classical psychological regularity, that the subject reacts much more often when he is the only witness of the theft than when there are three witnesses. However, if the respondents were only reported the situation (some heard that they were the only witnesses and others that they were one of three witnesses) and later on were asked how they would behave, the information about the number of witnesses was of no importance for their answers.

Another example of such discrepancies is the results of research in the area of social influence techniques. One such technique assumes that in order to increase the chances of fulfilling a request, a person's arm or forearm should be gently touched while asking it. Research conducted in various countries around the world has shown that this rule works regardless of the gender of the person making the request and the gender of the person to whom the request is addressed (e.g., Erceau \& Gueguen, 2007; Goldman, Kiyohara, \& Pfannensteil, 1985; Hornik, 1987). In an experiment carried out in Poland (Doliński, 2010), this relationship turned out to be slightly more complex. In this study, a young person (depending on the experimental conditions, a woman or a man) ap- proached a lone passer-by (a woman or a man) near the railway station and asked him to send a letter. The person explained that he/she wanted the letter to have the stamp of the local post office on the envelope, and he/she would not be able to send it him/ herself, as he/she was in a great hurry to catch the train. In half of the cases, the experimenter touched the arm or forearm of the person being requested, and in the remaining cases he/she did not do so. In the envelope there was a card with the description of the experimental conditions (e.g. "experimenter Eve asked a man while touching his arm"), and all letters were directed to the same address in another city. This allowed us to see not only how many people took letters from the experimenter, but also how many of them actually sent the letter. It turned out that touching increases the chances of fulfilling the request (both regarding taking a letter from the experimenter and sending it) in only three out of four situations. This was the case in both situations where the request was made by a woman, and also in the situation where a man asked a woman. However, if a man made a request to another man, touching the arm or forearm of the respondent even reduced the chances of fulfilling the request. (Additional research has shown that this is related to strong male homophobia in Poland.)

Postgraduate students were described the idea of this experiment (but without presenting its results) and asked to imagine that someone of the same sex as them (and in alternative conditions: of a different sex than them) asks them to send a letter. The respondents were supposed to answer whether the fact that the person addressing them would touch them on the arm or forearm while making this request would change the probability that they would take the letter from them. The respondents were supposed to choose one of three options: this factor will reduce the chances of taking the letter, increase them, or will not have any effect. It turned out that the vast majority of the surveyed women were convinced that regardless of the gender of the person making the request, they would react less favourably if a stranger touched them. In the case of men, the situation proved to be more complex. Most of them thought that a woman's touch would not have any impact on their reaction, and the beliefs of the others were evenly distributed - almost exactly the same number of respondents believed that touch would help a woman to achieve a goal, or believed that it would reduce the chances that they would decide to help her. When men were considering a situation in which a different man turns to them, they were most frequently convinced that touch would not have any relevance. However, nearly the same number of male respondents claimed that another man's touch would discourage them from fulfilling his request. Only two men (out of 84 respondents) assumed that another
Do psychologists study behaviour? 
man's touch would increase their chances of acting empathically.

Therefore, we can see that the relationship between the real situation and the appropriateness of imagining one's own reaction proved to be very complex. In women's opinion, touch, a factor that clearly increased the chances of fulfilling a request in the experiment in which we examined real behaviours, has the status of an element that reduces the chances of acting empathically. Men, in turn, make fewer mistakes in this matter. Although they underestimate the role that can be played by a woman's touch, in the conditions under which they are supposed to imagine that another man is touching them, their predictions are, essentially, correct. There are clearly more respondents here who think that touch in this case would reduce the chances of fulfilling the request than those who think that it would have a facilitating role.

Another, perhaps even more spectacular example of the discrepancy between how people behave in real situations and how they state they would behave is the classical research on obedience carried out subject to the Milgram paradigm (1974). Grzyb and Doliński (2017) showed that even in people who know Milgram's research well, there is a dominant belief that they would very quickly, at the very beginning of the experiment, refuse to follow the experimenter's instructions.

The question of the relationship between the actual behaviour and verbal statements about one's own behaviour can also be looked at from another perspective. A review of cross-cultural research (Peng, Nisbett, \& Wong, 1997) shows that when people living in different cultures are compared on the basis of their verbal declarations, a completely different picture is obtained than when their real behaviour is compared. This applies to such different areas of life as good table manners, time spent on sporting activities or maintaining cleanliness and order.

There is also a clear discrepancy between verbal declarations and the actual behaviour in health psychology. It has to be emphasized that this problem has a very significant practical meaning. In accordance with the World Health Organization report, "increasing the effectiveness of adherence interventions may have a far greater impact on the health of the population than any improvement in specific medical treatment" (Sabate, 2003, p. 13). Meanwhile, reliable research on fulfilment of medical recommendations by patients has revealed that on average every second patient does not take all prescribed medications during treatment, despite reporting doing so when speaking to a doctor (Cramer, 1998; Haynes, Taylor, \& Sackett, 1979).

Health psychologists "sin" in the same way as social ones. They tend to ask people what they eat, how often they exercise, how many cigarettes they smoke and how much alcohol they drink, rather than verify the truth. And the truth may be (and probably is) much worse than the researchers think...

Why don't social psychologists investigate real behaviours even where they explicitly declare in articles that they study them, but in reality they only ask people how they would behave in a particular situation? There seem to be at least two reasons for that. First, the study of real behaviour is much more difficult and time-consuming than the study of verbal declarations. What is the other reason? Behaviour is usually observed on an either/or basis. Someone helped a blind man cross the street, or did not. Someone gave back a pen found in a university corridor, and someone else did not. Someone took (or did not take) part in elections, someone took part in street protests, and someone else signed a petition. Someone changed money for somebody else, or did not, someone stopped the car to help an unfortunate man whose car broke down in the middle of the street, and someone else did not. Therefore, the key point is, whether - for example someone in the given circumstances acted altruistically or not (e.g. by giving a donation or not), and if someone behaved fairly in the given situation or not (e.g. by stealing the money or not). This dichotomous nature of the dependent variable, however, excludes the possibility of using many sophisticated statistical analyses (or enables such, but only with large samples examined, which is extremely cumbersome due to the above-mentioned workload related to conduction of the studies themselves). Therefore, if the researcher wants to obtain some meaningful result, he prefers to avoid the zero-one dependent variable. However, the problem is that if we adjust the method to the possibility of carrying out appropriate analyses, rather than look for such statistical models that would allow us to examine reality, we end up with absurdity. Therefore, avoiding the situation when the dependent variable is dichotomous, and planning research in such a way that behaviour can be studied on an interval scale, is reducing experimental research to absurdity. It is the method of data analysis that should be adjusted to the given research problem, not the problem that is determined and empirically operationalised so that the results can be easily quantified. To put it simply, it should be the dog wagging its tail, not the tail wagging the dog.

Moreover, it is highly problematic for social psychologists to treat the measurement scales used in psychological research, which measure the supposed behaviour, and in fact the declared tendency to certain behaviours, as interval scales. A scale in which we would ask, for example, "What amount of money (from 0 to 100 PLN) would you allocate to charity?" is only seemingly an interval scale. In fact, the difference between 0 and 1 is only mathematically the same as the difference between, say, 33 and 34 . In fact, there is a huge qualitative difference between 0 and 1 : nothing vs. something - refusal to support vs. com- 
mitment. The same applies to cheating. Cheating once every ten times is a big difference from not cheating once, and there is little difference between cheating six times and cheating seven times.

Which research paradigm is dominant in social psychology today? If we look at the papers from the world's leading periodicals, we will see that this is an approach based on measuring with questionnaires almost everything that seems to make sense from a theoretical perspective, and showing the results in the form of complex models, full of arrows and numbers. It is best to present complex models containing numerous mediators and moderators. "Without mediation, there are no publications" - as researchers say today to meet the needs of reviewers and editors and publish papers with figures so complex that almost no one can understand their meaning.

There is another serious problem with the research methodology prevailing nowadays in social psychology and based on filling in a battery of questionnaires. It is obvious that under such conditions artefacts may appear, due to the fact that tired or impatient subjects are becoming less and less attentive and increasingly careless. However, apart from this otherwise obvious problem, there is another one that does not attract attention and which seems to me much more serious.

According to Werner Karl Heisenberg's uncertainty principle (1927), the measurement can disturb the condition of the object being measured. In relation to psychology, this means that by measuring (e.g. with questionnaires, by interview or psychophysiological apparatus) human attitudes or behaviours, we change their course. In other words, this course is different when we measure it, and different when we do not measure it. The uncertainty principle also applies to studies in which people are first asked to self-describe themselves in a questionnaire, and then they study the behaviour semantically related to that self-description. Let us imagine, therefore, that the dependent variable is altruism or honesty (in this case, regardless of whether real or merely declared), and the self-descriptive questionnaires previously filled in by the persons examined include questions about such values as morality or altruistic attitudes towards people, and altruistic behaviour. By answering the questionnaire, the subjects reflect on what they are like, and thus search their memory for events that allow them to find answers to these questions. As a consequence, they start to perceive themselves as "not very altruistic" or "mostly honest". According to the experimental scheme adopted by the researcher, the subjects are then supposed to make a decision about their behaviour (or they are wondering how they would behave). The mental availability of the answers given in the questionnaire will now clearly influence this crucial stage of the experiment. The important question is therefore whether the observed results should not appear solely because the experimenter has asked the subjects to fill in the self-report questionnaire. In other words, is it not the content of the questionnaire alone that makes the persons examined consider, among other things, whether they are altruistic or honest and then behave in a certain way. Perhaps if the persons examined did not fill in this questionnaire, they would not think about what they are like, and thus would not behave in accordance with this statement moments later. Speaking otherwise, it could be so, that it is not (as the experimenter assumes) a given measured attribute, attitude or value that influences the subjects' behaviour, but only a temporary concentration of the subjects on specific content, which is unintentionally triggered by the experimenter (see also Ossowski, 1962/1967).

Hence, if we introduce mediators and moderators into the experimental scheme, we should also have such conditions in the scheme, where these elements do not exist (respondents do not fill in any questionnaires)! And only if it turns out that the influence of the independent variable on the dependent one is the same in the conditions of the lack of measurements of mediators and moderators, as well as in the conditions of the presence of this element, can we then reject the thesis that only the mere fact of the respondents filling in the appropriate questionnaire influenced their behaviour. It seemed quite obvious. However... This is not the way things are done in social psychology.

Let me make myself clear. I absolutely do not question the need to study other aspects of human functioning than real behaviour. I do not have the slightest doubt that social psychology should study attitudes, stereotypes, content and functions of the "self" structure, generalised beliefs about the social world or values. Psychology does not have to draw conclusions about behaviours in a direct way. Losing weight by $10 \mathrm{~kg}$ in a month may be an equally good indicator of going on a diet as the observation that the respondent stopped binge-eating; lower energy bills will be an excellent indicator of saving energy. When investigating altruism, we do not have to see that the respondent is currently making a donation to charity. It is enough if we confirm that he really made such a bank transfer.

Nevertheless, the main problem is that in psychology it is not verified whether people made the bank transfer. Instead, people are asked if they would do it. Instead... This is why I call such studies "research instead".

\section{FUNDING}

The article was written as part of the grant 2018/29/B/ HS6/00543 awarded by the National Science Centre.
Do psychologists study behaviour? 


\section{REFERENCES}

Baumeister, R. F., Vohs, K. D., \& Funder, D. C. (2007). Psychology as the science of self-reports and finger movements: Whatever happened to actual behaviour? Perspectives on Psychological Science, 2, 396403. https://doi.org/10.1111/j.1745-6916.2007.00051.x

Cramer, J. A. (1998). Enhancing patient compliance in the elderly. Role of packaging aids and monitoring. Drugs \& Aging, 12, 7-15. https://doi. org/10.2165/00002512-199812010-00002

Deutsche Bank (2014). Financial report of Poles 2014. Plans for 2015. Retrieved from https://www.deutschebank.pl/raport-portret-finansowy-polakow-2014.pdf

Doliński, D. (2010). Touch, compliance, and homophobia. Journal of Nonverbal Behavior, 34, 179-192. https://doi.org/10.1007/s10919-010-0090-1

Doliński, D. (2018a). Is psychology still a science of behaviour? Social Psychological Bulletin, 13, article e25025. https://doi.org/10.5964/spb.v13i2.5205.

Doliński, D. (2018b). Social psychology should be a science of feelings, thoughts and behaviour. Social Psychological Bulletin, 13, article e26133. https://doi. org/10.5964/spb.v13i2.26133.

Erceau, D., \& Gueguen, N. (2007). Tactile contact and evaluation of the toucher. Journal of Social Psychology, 147, 441-444. https://doi.org/10.3200/ SOCP.147.4.441-444

Goldman, M., Kiyohara, O., \& Pfannensteil, D. A. (1985). Interpersonal touch, social labeling, and the foot-in-the-door effect. Journal of Social Psychology, 125, 143-147. https://doi.org/10.1080/0022 4545.1985.9922866

Grzyb, T. (2016). Why can't we just ask? The influence of research methods on results. The case of "bystander effect". Polish Psychological Bulletin, 47, 233-235. https://doi.org/10.1515/ppb-2016-0027

Grzyb, T., \& Doliński, D. (2017). Beliefs about obedience levels in studies conducted within the Milgram paradigm: Better than average effect and comparisons of typical behaviors by residents of different countries. Frontiers in Psychology, 8, 1632. https://doi.org/10.3389/fpsyg.2017.01632

Haynes, R. B., Taylor, D. W., \& Sackett, D. L. (1979). Compliance in health care. Baltimore, MD: Johns Hopkins University Press.

Heisenberg, W. (1927) Ueber den anschaulichen Inhalt der quantentheoretischen Kinematik und Mechanik [About the descriptive content of quantum theoretical kinematics and mechanics]. Zeitschrift für Physik, 43, 172-198. https://doi.org/10.1007/ BF01397280

Hornik, J. (1987). The effect of touch and gaze upon compliance and interest of interviewees. Journal of Social Psychology, 127, 681-683.

Kaplan, H. R. (1987). Lottery winners: The myth and reality. Journal of Gambling Behavior, 3, 168-178. https://doi.org/10.1007/BF01367438
Milgram, S. (1974). Obedience to authority: an experimental view. New York: Harper and Row.

Motyl, M., Demos, A. P., Carsel, T. S., Hanson, B. E., Melton, Z. J., Mueller, A. B., Prims, J. P., Sun, J., Washburn, A. N., Wong, K. M., Yantis, C., \& Skitka, L. J. (2017). The state of social and personality science: Rotten to the core, not so bad, getting better, or getting worse? Journal of Personality and Social Psychology, 113, 34-58. https://doi.org/10.1037/ pspa0000084

Ossowski, S. (1962/1967). O osobliwościach nauk społecznych [About the peculiarities of social sciences]. In S. Ossowski (Ed.), Dzieła [Works] (Vol. 4, pp. 125-316). Warszawa: Państwowe Wydawnictwo Naukowe.

Peng, K., Nisbett, R. E., \& Wong, N. Y. C. (1997). Validity problems comparing values across cultures and possible solutions. Psychological Methods, 2, 329-344. https://doi.org/10.1037/1082-989X.2.4.329

Sabate, E. (2003). Adherence to long-term therapies. Evidence for action. Geneva: World Health Organization. 